\title{
Hyperosmotic response of streptococcus mutans: from microscopic physiology to transcriptomic profile
}

Chengcheng $\mathrm{Liu}^{1 \dagger}$, Yulong Niư ${ }^{2 \dagger}$, Xuedong Zhou ${ }^{1}$, Keke Zhang ${ }^{1}$, Lei Cheng ${ }^{1}$, Mingyun $\mathrm{Li}^{1}$, Yuqing $\mathrm{Li}^{1}$, Renke Wang ${ }^{1}$, Yi Yang ${ }^{2}$ and Xin $\mathrm{Xu}^{1 *}$

\begin{abstract}
Background: Oral streptococci metabolize carbohydrate to produce organic acids, which not only decrease the environmental pH, but also increase osmolality of dental plaque fluid due to tooth demineralization and consequent calcium and phosphate accumulation. Despite these unfavorable environmental changes, the bacteria continue to thrive. The aim of this study was to obtain a global view on strategies taken by Streptococcus mutans to deal with physiologically relevant elevated osmolality, and perseveres within a cariogenic dental plaque.

Results: We investigated phenotypic change of S. mutans biofilm upon hyperosmotic challenge. We found that the hyperosmotic condition was able to initiate $S$. mutans biofilm dispersal by reducing both microbial content and extracellular polysaccharides matrix. We then used whole-genome microarray with quantitative RT-PCR validation to systemically investigate the underlying molecular machineries of this bacterium in response to the hyperosmotic stimuli. Among those identified 40 deferentially regulated genes, down-regulation of gtfB and comC were believed to be responsible for the observed biofilm dispersal. Further analysis of microarray data showed significant up-regulation of genes and pathways involved in carbohydrate metabolism. Specific genes involved in heat shock response and acid tolerance were also upregulated, indicating potential cross-talk between hyperosmotic and other environmental stress.

Conclusions: Hyperosmotic condition induces significant stress response on S. mutans at both phenotypic and transcriptomic levels. In the meantime, it may take full advantage of these environmental stimuli to better fit the fluctuating environments within oral cavity, and thus emerges as numeric-predominant bacterium under cariogenic conditions.
\end{abstract}

Keywords: Streptococcus mutans, Hyperosmotic condition, Transcriptional profile, Biofilm dispersal, Environmental fitness, Dental plaque

\section{Background}

Dental plaque is a densely-packed microbial biofilm and the residents living inside lead a "famine and feast" life style due to the fluctuation of nutrients within the oral cavity [1]. In addition to many commonly studied environmental stimuli such as acidic and hyperthermic conditions to which dental plaque residents are frequently exposed, osmotic stress is also believed to have a great impact on dental plaque ecology and the development

\footnotetext{
* Correspondence: nixux1982@hotmail.com

${ }^{\dagger}$ Equal contributors

'State Key Laboratory of Oral Diseases, West China Hospital of Stomatology, Sichuan University, Chengdu, PR China

Full list of author information is available at the end of the article
}

of dental caries [2]. Acidogenic bacteria within dental plaque are able to metabolize carbohydrate to produce organic acids, which not only decrease the environmental $\mathrm{pH}$, but also increase ionic strength of the plaque fluid due to tooth demineralization and consequent calcium and phosphate accumulation [3]. It has been reported that the ionic strength of plaque fluid is doubled after sugar challenges, increasing from roughly $150 \mathrm{mM}$ to approximately $300 \mathrm{mM}[3,4]$. Thus, persistent residents within dental plaque have likely evolved sophisticated molecular machineries to counter the detrimental effect of elevated osmolality on their growth.

\section{Biomed Central}

(c) 2013 Liu et al.; licensee BioMed Central Ltd. This is an open access article distributed under the terms of the Creative Commons Attribution License (http://creativecommons.org/licenses/by/2.0), which permits unrestricted use, distribution, and reproduction in any medium, provided the original work is properly cited. 
S. mutans is normal resident in the dental plaque and has been considered as the primary causative agent of dental caries for decades. S. mutans is able to take advantage of low $\mathrm{pH}$ to emerge as numerically predominant resident in cariogenic plaque $[1,2]$. In addition, S. mutans has developed intricate machineries to counter those detrimental environmental challenges such as hyperosmotic stress, in order to persevere within the dental plaque $[1,5]$. Many microorganisms respond to hyperosmotic challenges by increasing the intracellular levels of $\mathrm{K}^{+}$and accumulating compatible solutes [6,7]. The complete genome sequence of $S$. mutans has revealed several genes sharing homology with $\mathrm{K}^{+}$transporters and the Opu family of ABC transporters of Escherichia Coli $[8,9]$. These findings suggest that $S$. mutans may rally a series of intricately regulated genes and pathways to internalize $\mathrm{K}^{+}$and compatible solutes, and thus perseveres under hyperosmotic conditions. A previous study from Burne's group has identified a few candidates involved in the hyperosmotic stress response of $S$. mutans, and a possible cross-talk between osmotic and oxidative stress responses in S. mutans has also been suggested [10]. However, the traditional "hypothesis-driven approach" to investigating selected genes sharing homology with stress response related genes of model bacteria may not suffice to give a global knowledge about the strategies used by this caries pathogen to cope with hyperosmotic challenges.

Although a number of studies have described transcriptional responses of $S$. mutans under various conditions [11-15], the molecular response of this bacterium under physiologically relevant hyperosmotic condition has not been profiled at transcriptomic level. In this study, we used microarray to profile the transcriptome of $S$. mutans under hyperosmotic conditions. Several genes and pathways were identified and further correlated with phenotypic changes of the organism observed under hyperosmotic challenges. The aim of this work is to provide a comprehensive insight into the sophisticated machineries adopted by $S$. mutans to better fit the physiologically relevant elevated osmolality, and thus perseveres within the oral cavity.

\section{Results and discussion}

\section{Hyperosmotic conditions initiate biofilm dispersal}

By constructing the growth curve of $S$. mutans under increasing concentrations of $\mathrm{NaCl}$, we found that $0.4 \mathrm{M}$ of $\mathrm{NaCl}$ provided the sub-inhibitory level of osmolality that slightly retarded the growth rate of $S$. mutans (Figure 1A). We thus chose this concentration of $\mathrm{NaCl}$ for the rest of study. We investigated the short-term and long-term effects of $0.4 \mathrm{M}$ of $\mathrm{NaCl}$ on the biofilm configuration of $S$. mutans. Hyperosmotic conditions significantly inhibited the biomass of $S$. mutans biofilm, and this inhibitory effect was time and concentration-dependent (Figure 1B and C). In addition, we performed live/dead fluorescence stain of biofilm and enumerated the biofilm colony forming unit (CFU), and we found that either the percentage or absolute number of viable cells after exposure to $0.4 \mathrm{M}$ $\mathrm{NaCl}$ was comparable to that of non-treated control (Figure 1D and E). These data indicate that the observed biomass reduction after hyperosmotic exposure was less likely caused by growth inhibition, but more likely attributed to the dispersal of biofilm under adversary conditions. The osmolality-provoked biofilm dispersal was further confirmed with fluorescence double-labeling and scanning electronic microscopy (Figure 2). Exposure to sub-inhibitory level of hyperosmotic stimuli not only inhibited cellular components within the biofilm, but also reduced the extracellular polysaccharides (EPS) matrix synthesized.

To better understand the underlying molecular machineries, we performed whole-genome microarray analysis to profile the transcriptomic changes of $S$. mutans upon short term exposure $(15 \mathrm{~min})$ to $0.4 \mathrm{M}$ of $\mathrm{NaCl}$. We identified 40 genes with $\geq 2$ fold changes, among which 14 genes were up-regulated and 26 genes were down-regulated (Table 1 and Additional file 1). Specific genes were further quantified by quantitative RT-PCR, and the results showed acceptable consistency with the microarray data (Figure 3). In agreement with the observed biofilm dispersal phenotype, a significant downregulation of glycosyltransferase $B$ encoding gene $(\mathrm{gtf} B$ ) was identified (Table 1 and Figure 3). Glycosyltransferase $\mathrm{B}$ is the major enzyme responsible for the EPS synthesis, mediating the cellular adherence and biofilm formation of S. mutans [16]. By down-regulating gtfB expression under hyperosmotic conditions, bacterial cells are more ready to "break their biofilm bonds", leading to a less condensed microbial community with reduced biomass. In addition, we also found that a competence-stimulating peptide (CSP) encoding gene, $\operatorname{com} C$ was down-regulated upon $15 \mathrm{~min}$ exposure to $0.4 \mathrm{M}$ of $\mathrm{NaCl}$ (Table 1). The CSP is a member of bacterial quorum sensing system. It has been reported to be involved in competence development, acid tolerance and biofilm formation of $S$. mutans [17]. Importantly, recent findings from Lévesque's group have demonstrated that high level of CSP may act as an "alarmone", triggering "guard cells" autolysis and release of eDNA necessary for the genetic diversity and survival of whole community $[18,19]$. The down-regulation of $\operatorname{com} C$ may promote the conversion of $S$. mutans cells from a static community-based lifestyle to a more motile planktonic lifestyle. Therefore, the significant downregulation of $g t f B$ and $\operatorname{com} C$ further supports our phenotypic observation that hyperosmotic challenges initiated biofilm dispersal.

It's noteworthy that a recent transcriptomic profiling of $S$. mutans in the presence of oxygen also showed 


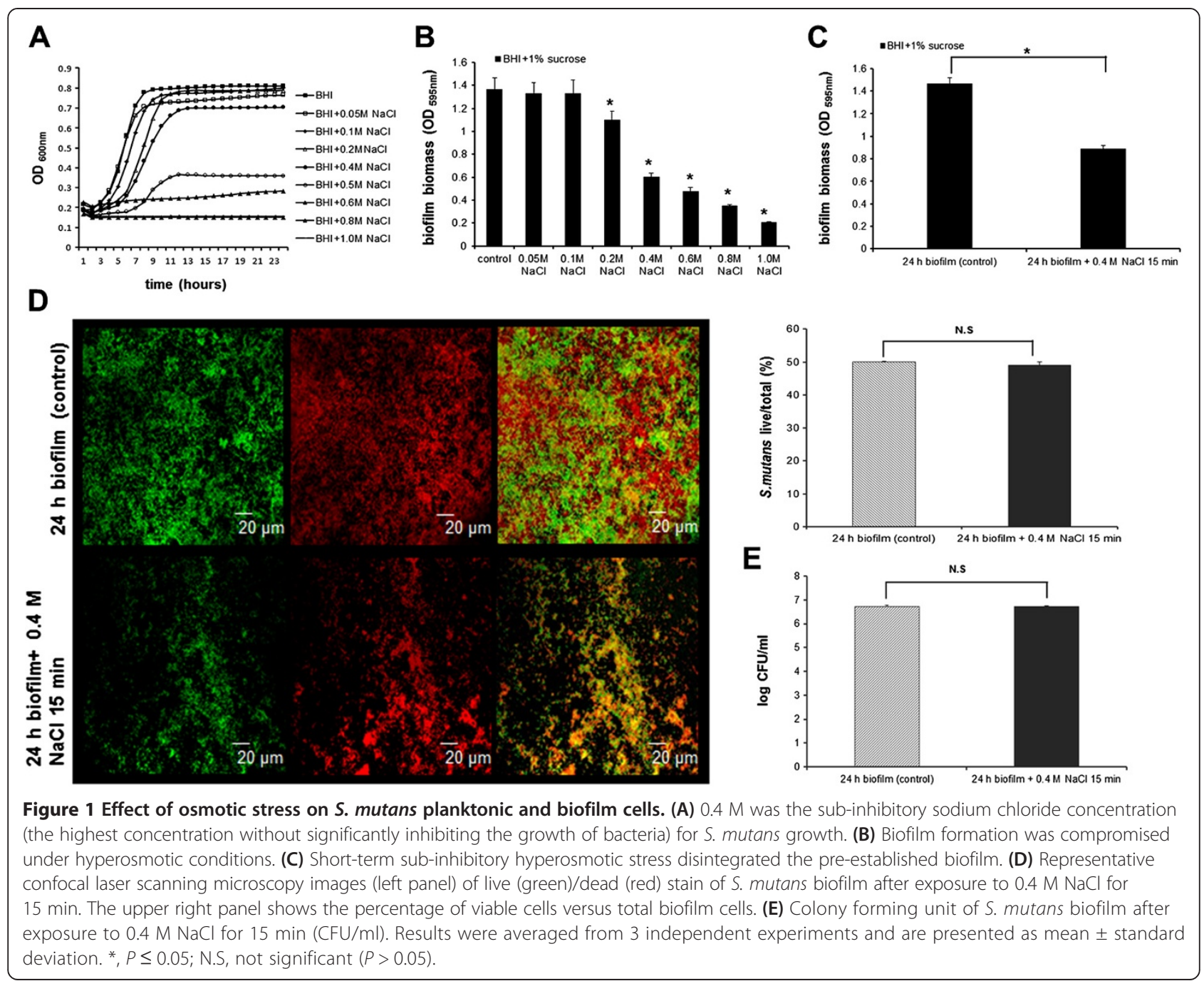

significant down-regulation of $\operatorname{gtfB}$ and genes involved in ComCDE quorum sensing system [13]. This suggests that a motile lifestyle may be a common strategy employed by $S$. mutans to adapt adversary conditions.

\section{S. mutans increases carbohydrates consumption in response to hyperosmotic challenge}

Most bacteria do not possess active water transport mechanisms to maintain cell turgor, which is essential for survival [20]. Instead, bacteria usually pool "compatible solutes" to deal with hyperosmotic conditions. Although some compatible solutes, such as glycine betaine and carnitine, can be synthesized and accumulated intracellularly during osmotic stress, bacteria also adopt efficient transport systems to internalize necessary compounds to counter hyperosmotic stress [6]. Burne's previous study has suggested that $S$. mutans may take up compatible solutes from the environment by up-regulating the $A B C$ transporter homologous genes (орсA and opuAA) upon short-term exposure to hyperosmotic challenge [10].
Although no significant up-regulation of compatible solutes internalization related genes was detected by our high throughput transcriptomic profiling at a differentiation power of $\geq 2$ fold changes, genes involved in the phosphotransferase system (PTS) and carbohydrate metabolism were significantly up-regulated upon short-term hyperosmotic challenge (Table 1). We further categorized the majority of those differentially expressed genes into 12 KEGG pathways. We found that pathways involved in carbohydrates consumption, including PTS, galactose metabolism, fructose/mannose metabolism, and pyruvate metabolism were significantly up-regulated (Figure 4). Based on these findings, we propose that in order to counter the detrimental effects of short-term hyperosmotic challenge, S. mutans needs to actively internalize compatible solutes to recover from hyperosmotic stress. In the meantime, the bacterial cells have to up-regulate genes involved in carbohydrates transportation and metabolism, so as to couple the increased demand for ATP consumption. 

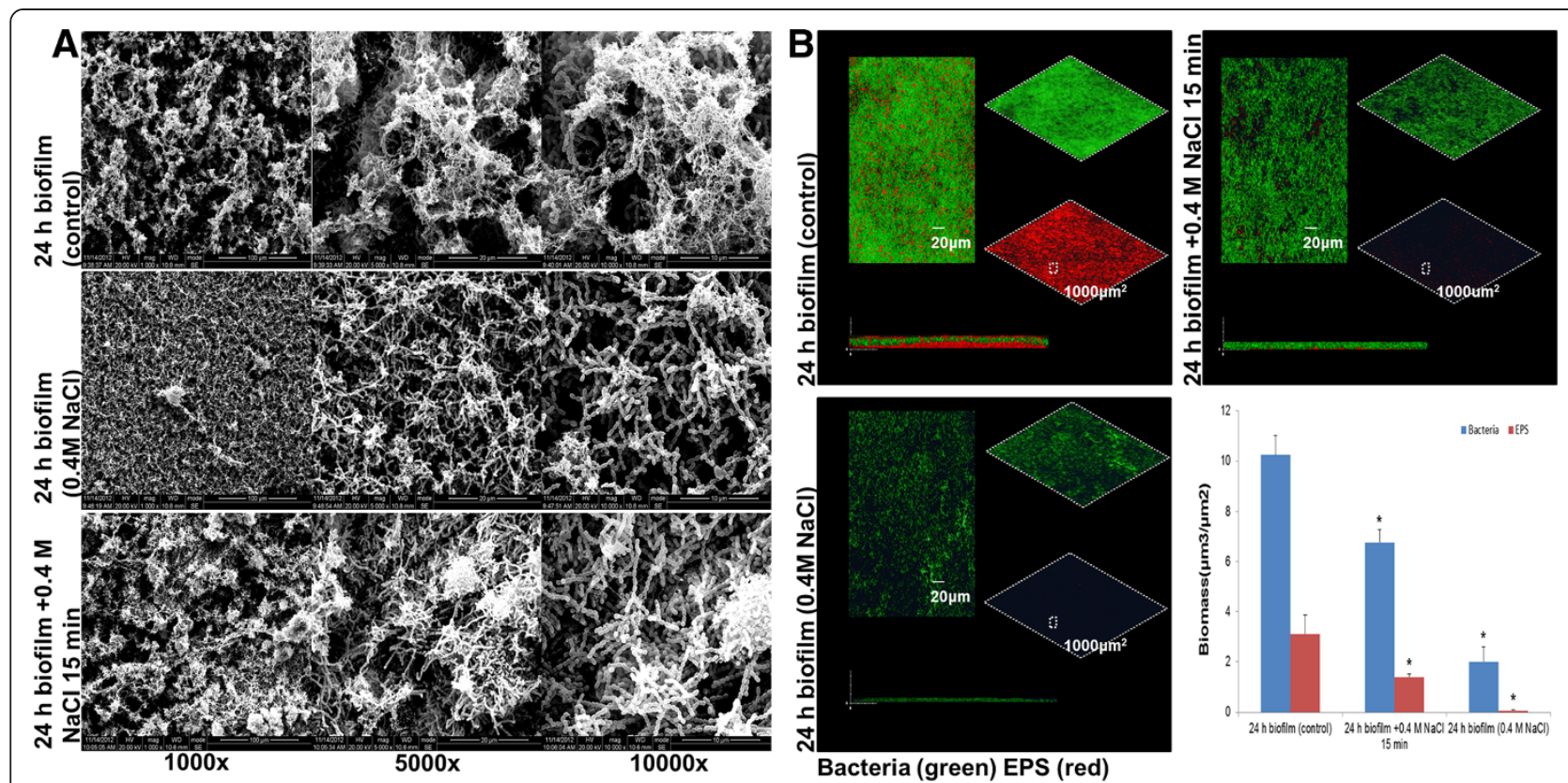

Figure 2 Phenotypic characteristics of S. mutans after short-term and long-term hyperosmotic stimuli. (A) Representative Scanning Electronic Microscopy images of S. mutans biofilm on glass surfaces. Images shown were taken at $1000 \times, 5000 \times$ and $10000 \times$ magnification. (B) Representative 3D rendering images of S. mutans biofilms without $\mathrm{NaCl}$ for $24 \mathrm{~h}$ (upper left), versus with $0.4 \mathrm{M} \mathrm{NaCl}$ for either 15 min (upper right) or $24 \mathrm{~h}$ (lower left). Bacterial cells and EPS are in situ labelled. Green, the bacteria (SYTO 9); red, the EPS (Alexa Fluor 647). At the right of each panel, the two channels are displayed separately, while the merged image is displayed at the left. Lateral (side) views of each biofilm are displayed at the bottom. Quantitative determination of S. mutans biofilms (lower right) confocal image stacks analyzed by the image-processing software COMSTAT. Results were averaged from 3 independent experiments and are presented as mean \pm standard deviation. ${ }^{*}, P \leq 0.05$.

Interestingly, most of these aforementioned carbohydrates metabolism related genes and pathways are also up-regulated during oxygen challenge [13], further suggesting that $S$. mutans has developed sophisticated energy mobilization strategy to counter environmental adversity.

\section{Hyperosmotic challenge prepares $S$. mutans for better fitness under multiple environmental stimuli}

As mentioned above, several genes involved in the carbohydrate metabolism of S. mutans were up-regulated. S. mutans may take full advantage of this increased energy generation to cope with multiple environmental stimuli. Previously study from Burne's group has shown that two oxidative stress genes, sodA and nox were induced during hyperosmotic stress, and certain up-regulated gene (Smu.2115) upon hyperosmotic challenges was also involved in acid/oxidative stress responses [10]. These findings suggest a potential cross-talking between hyperosmotic stress responses and other environmental responses of $S$. mutans. In the current study, we found that Lactoylglutathione lyase (lgl, smu1603), and $C l p B$ (smu1425) were significantly induced during hyperosmotic stress (Table 1 and Figure 3). $l g l$ has been shown to play an essential role in the acid tolerance response of $S$. mutans by detoxifying cytotoxic metabolite methyglyoxal in the cytoplasm [21]. Therefore, upregulation of $l g l$ under hyperosmotic conditions may enhance the aciduricity of $S$. mutans. $C \operatorname{lpB}$ encodes a chaperone subunit with two ATP-binding domains involved in heat shock response [9]. Previous study from Burne's group has also shown a significant up-regulation of $C l p B$ in $S$. mutans during oxygen challenge [13]. The up-regulation of $C l p B$ upon hyperosmotic challenge may assist unfolding the denatured protein amassed during environment stimuli, thus promoting the fitness of $S$. mutans under other detrimental conditions such as oxidative and heat stresses.

On the other hand, it has been demonstrated that dispersal cells from bacterial biofilm can colonize different and/or more niches than the bacteria that initiated the original biofilm, leading to better fitness of those bacteria in the environment [22]. The induced dispersal of $S$. mutans biofilm under hyperosmotic stress may to an extent enhance the colonizing capacity of $S$. mutans cells, leading to a potential "niche expansion", and thus benefit its fitness under the fluctuating environment within the oral cavity.

\section{Conclusion}

Taken together, this study has investigated phenotypic and transcriptional effects of hyperosmotic stress on 
Table 1 Selected genes up- or down-regulated 2-fold or more under hyperosmotic stress

\begin{tabular}{|c|c|c|c|c|}
\hline GENE & GENE_INFO & Functional annotation & FC: (class1/class2) & pfp (Q.value) \\
\hline SMU_117C & GenelD:1029696 & Hypothetical protein & 3.0733 & 0.0066 \\
\hline SMU_500 & GenelD:1029501 & Putative ribosome-associated protein & 2.7709 & 0.0123 \\
\hline SMU_115 & GenelD:102969 & Putative PTS system & 2.6848 & 0.0153 \\
\hline SMU_1603 & GenelD:1028837 & Putative lactoylglutathione lyase & 2.5786 & 0.018 \\
\hline SMU_378 & GenelD:1027825 & Hypothetical protein & 2.6647 & 0.0184 \\
\hline SMU_1402C & GenelD:1028098 & Hypothetical protein & 2.5215 & 0.033 \\
\hline SMU_116 & GenelD:1029694 & Tagatose 1 & 2.3508 & 0.0641 \\
\hline SMU_376 & GenelD:1028099 & $\mathrm{N}$-acetylornithine aminotransferase & 2.2209 & 0.0564 \\
\hline SMU_1425 & GenelD:1028678 & Putative Clp proteinase & 2.0849 & 0.083 \\
\hline SMU_930C & GenelD:1028282 & Putative transcriptional regulator & 2.2036 & 0.101 \\
\hline SMU_1403C & GenelD:1029503 & Hypothetical protein & 2.1238 & 0.1002 \\
\hline SMU_1568 & GenelD:1028671 & Putative maltose/maltodextrin $\mathrm{ABC}$ transporter & 2.0175 & 0.0932 \\
\hline SMU_292 & GenelD:1027867 & Putative transcriptional regulator & 2.0309 & 0.0987 \\
\hline SMU_1704 & GenelD:1028933 & Hypothetical protein & 2.0003 & 0.0999 \\
\hline SMU_1286c & GenelD:1029427 & Putative permease; multidrug efflux protein & 0.321 & 0.025 \\
\hline SMU_669c & GenelD:1028087 & Putative glutaredoxin & 0.3331 & 0.0156 \\
\hline SMU_1915 & GenelD:1029111 & Competence stimulating peptide & 0.3134 & 0.0169 \\
\hline SMU_1438c & GenelD:1028690 & Putative $\mathrm{Zn}$-dependent protease & 0.3174 & 0.0186 \\
\hline SMU_1127 & GenelD:1029483 & 30 S ribosomal protein $\mathbf{S} 20$ & 0.3818 & 0.0201 \\
\hline SMU_2083C & GenelD:1028336 & Hypothetical protein & 0.3697 & 0.0266 \\
\hline SMU_40 & GenelD:1029627 & Hypothetical protein & 0.3463 & 0.0263 \\
\hline SMU_1782 & GenelD:1028999 & Hypothetical protein & 0.3727 & 0.023 \\
\hline SMU_1072C & GenelD:1028400 & Putative acetyltransferase & 0.3326 & 0.0236 \\
\hline SMU_41 & GenelD:1029625 & Hypothetical protein & 0.376 & 0.0314 \\
\hline SMU_463 & GenelD:1029596 & Putative thioredoxin reductase (NADPH) & 0.3877 & 0.0289 \\
\hline SMU_954 & GenelD:1028304 & Pyridoxamine kinase & 0.3601 & 0.0364 \\
\hline SMU_2105 & GenelD:1029281 & Hypothetical protein & 0.4186 & 0.0397 \\
\hline SMU_1848 & GenelD:1029060 & Hypothetical protein & 0.3912 & 0.0372 \\
\hline SMU_924 & GenelD:1028271 & Thiol peroxidase & 0.4212 & 0.0492 \\
\hline SMU_2084C & GenelD:1029257 & Transcriptional regulator Spx & 0.4436 & 0.0505 \\
\hline SMU_953C & GenelD:1028336 & Putative transcriptional regulator/aminotransferase & 0.4009 & 0.0599 \\
\hline SMU_955 & GenelD:1029492 & Hypothetical protein & 0.3937 & 0.0584 \\
\hline SMU_2109 & GenelD:1029274 & Putative MDR permease; multidrug efflux pump & 0.4045 & 0.056 \\
\hline SMU_396 & GenelD:1029567 & Putative glycerol uptake facilitator protein & 0.5103 & 0.068 \\
\hline SMU_417 & GenelD:1027942 & Hypothetical protein & 0.4399 & 0.0771 \\
\hline SMU_29 & GenelD:1027942 & Phosphoribosylaminoimidazole-succinocarboxamidesynthase & 0.452 & 0.0806 \\
\hline SMU_1131C & GenelD:1028440 & Hypothetical protein & 0.4692 & 0.0805 \\
\hline SMU_1284C & GenelD:1029335 & Hypothetical protein & 0.4432 & 0.0849 \\
\hline SMU_758C & GenelD:1028150 & Hypothetical protein & 0.4976 & 0.0838 \\
\hline SMU_1004 & GenelD:1028336 & Glucosyltransferase-I & 0.5331 & 0.0962 \\
\hline
\end{tabular}

S. mutans, and revealed genes and pathways essential for the hyperosmotic tolerance in this caries associated bacterium. We believe that although hyperosmotic challenge may induce significant stress response on bacteria, S. mutans has evolved sophisticated molecular machineries to counter those elicited detrimental effects. Additionally, S. mutans can mobilize genes and pathways to take full advantage of these 


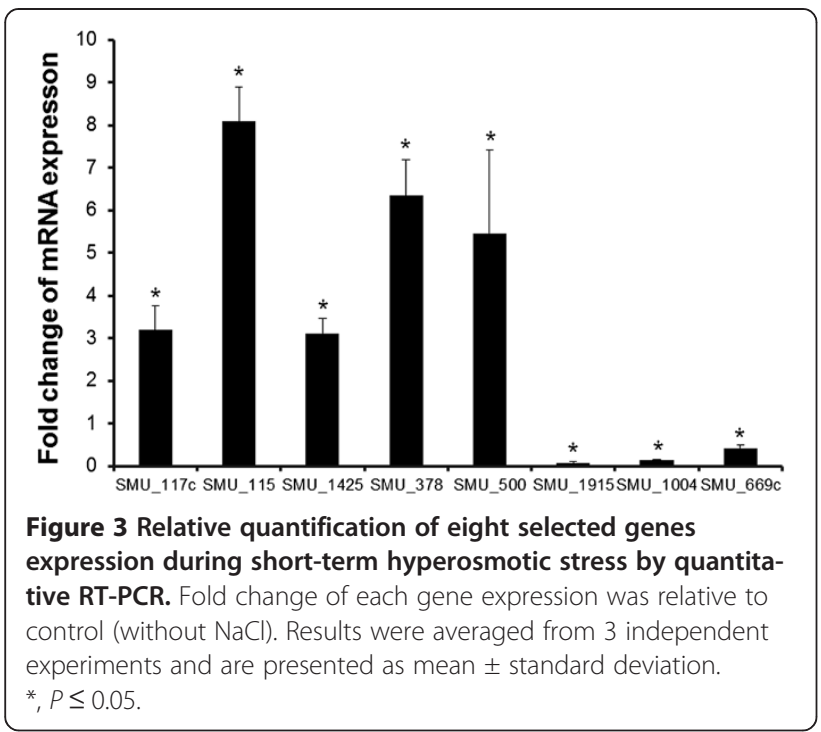

environmental stimuli to better fit the fluctuating environments within the oral cavity, and thus emerge as the numeric-predominant bacteria under cariogenic conditions such as frequent sugar uptake.

\section{Methods}

\section{Bacteria strains and culture conditions}

Streptococcus mutans UA159 was commercially obtained from the American Type Culture Collection (ATCC). Bacteria were grown in brain heart infusion broth (BHI; Difco, Sparks, MD, USA) at $37^{\circ} \mathrm{C}$ in a $5 \% \mathrm{CO}_{2}$ atmosphere until the cells reached the mid-logarithmic phase $\left(\mathrm{OD}_{600 \mathrm{~nm}}=\right.$ $0.5)$. To determine the sub-inhibitory level of hyperosmotic challenge, bacteria were grown in BHI supplemented with $0.05,0.1,0.2,0.4,0.5,0.6,0.8,1.0 \mathrm{M}$ of sodium chloride respectively. For in vitro biofilm establishment, bacterial cells were grown in BHI supplemented with $1 \%$ sucrose (wt/vol).

\section{Bacteria susceptibility assays}

The sub-inhibitory concentration of sodium chloride was determined by a microdilution method as described previously [23]. Growth curves of S. mutans UA159 were further constructed by monitoring the optical density $\left(\mathrm{OD}_{600 \mathrm{~nm}}\right)$ of the cultures for $24 \mathrm{~h}$ using a Bioscreen $\mathrm{C}$ analyzer (Oy Growth Curves AB Ltd., Finland) [24]. The formation of $S$. mutans biofilm under increasing concentrations of $\mathrm{NaCl}$ was quantified in a 96-well microtiter plate as described previously [25]. Briefly, S. mutans UA159 $\left(1 \times 10^{6} \mathrm{CFU} / \mathrm{ml}\right)$ was grown in BHI supplemented with $1 \%$ (wt/vol) sucrose and $\mathrm{NaCl}(0.05 \mathrm{M}$ to $1.0 \mathrm{M})$ at $37^{\circ} \mathrm{C}$ for $24 \mathrm{~h}$. The culture supernatant from each well was then decanted, and the adherent biofilm was washed three times with PBS, fixed with methanol for $15 \mathrm{~min}$, and stained with $0.1 \%$ (wt/vol) crystal violet
(Sigma-Aldrich Corp., St. Louis, MO, USA) for $5 \mathrm{~min}$. Subsequently, the wells were rinsed with deionized water until the blank wells appeared colorless; $200 \mu \mathrm{l}$ of $95 \%$ ethanol was added. The plates were shaken at room temperature for $30 \mathrm{~min}$, and the absorbance at $595 \mathrm{~nm}$ was recorded. The short-term effect of hyperosmotic challenge on the pre-established biofilm was also determined by quantification of the biomass of $24 \mathrm{~h} \mathrm{~S}$. mutans biofilm after exposure to $0.4 \mathrm{M} \mathrm{NaCl}$ for $15 \mathrm{~min}$ using the same method as described above. All the experiments were performed in three-replicates and the average was calculated.

\section{Biofilm viability assays}

$24 \mathrm{~h}$ pre-established $S$. mutans biofilms were treated with $0.4 \mathrm{M} \mathrm{NaCl}$ for $15 \mathrm{~min}$, gently harvested with a cell scraper, and suspended in PBS to an $\mathrm{OD}_{600 \mathrm{~nm}}$ of 1.0. The bacterial cells suspension was then serially diluted and plated in triplicate on BHI agar plates. After 48 hours incubation at $37^{\circ} \mathrm{C}\left(5 \% \mathrm{CO}_{2}\right)$, colony forming unit (CFU) of biofilms was enumerated.

The treated biofilms were also stained with a two-color fluorescence assay kit (LIVE/DEAD BacLight-Bacterial Viability Kit 7012, Invitrogen, Molecular Probes, Inc., Eugene, OR, USA) according to the manufacturer's instructions. The biofilms images were captured using a Leica TCS SP2 confocal laser scanning microscope (Leica, Germany), and the percentage of viable cells was calculated by Image Pro-Plus 6.0 (Media Cybernetics Inc., Bethesda, MD, USA).

\section{Microbial biofilm configuration}

Scanning electron microscopy (SEM) was performed as described previously [26] to investigate the configuration of $S$. mutans biofilm under hyperosmotic condition. $S$. mutans biofilms were either established on glass slides in the presence of $0.4 \mathrm{M}$ of $\mathrm{NaCl}$ for $24 \mathrm{~h}$, or pre-established $24 \mathrm{~h}$ biofilm on glass slides and then treated with $0.4 \mathrm{M}$ of $\mathrm{NaCl}$ for $15 \mathrm{~min}$. Biofilm samples were gently washed two times with sterile PBS to remove planktonic cells and fixed with $2.5 \%$ glutaraldehyde at $4^{\circ} \mathrm{C}$ overnight. The samples then were dehydrated in a graded series of ethanol $(50 \%, 60 \%, 70 \%, 80 \%$, $90 \%, 95 \%$ and $100 \%$ ), dried in a freeze dryer, gold coated and observed under a SEM (FEI, Hillsboro, OR, USA).

The biofilm samples were also double-labeled by the method as described by Koo et al. [27,28]. In brief, the extracellular polysaccharides matrix of $S$. mutans biofilm was labeled by incorporating $2.5 \mu \mathrm{mol} \mathrm{l^{-1 }}$ of Alexa Fluor 647-labelled dextran conjugate (10000 MW; absorbance/ fluorescence emission maxima of 650/668 nm; Molecular Probes Inc., Eugene, OR, USA) into the newly formed glucan. The bacterial cells in biofilms were labeled by means of SYTO 9 green fluorescent nucleic acid stain (2.5 $\mu \mathrm{mol} 1^{-1}, 480 / 500 \mathrm{~nm}$; Molecular Probes Inc.). The 


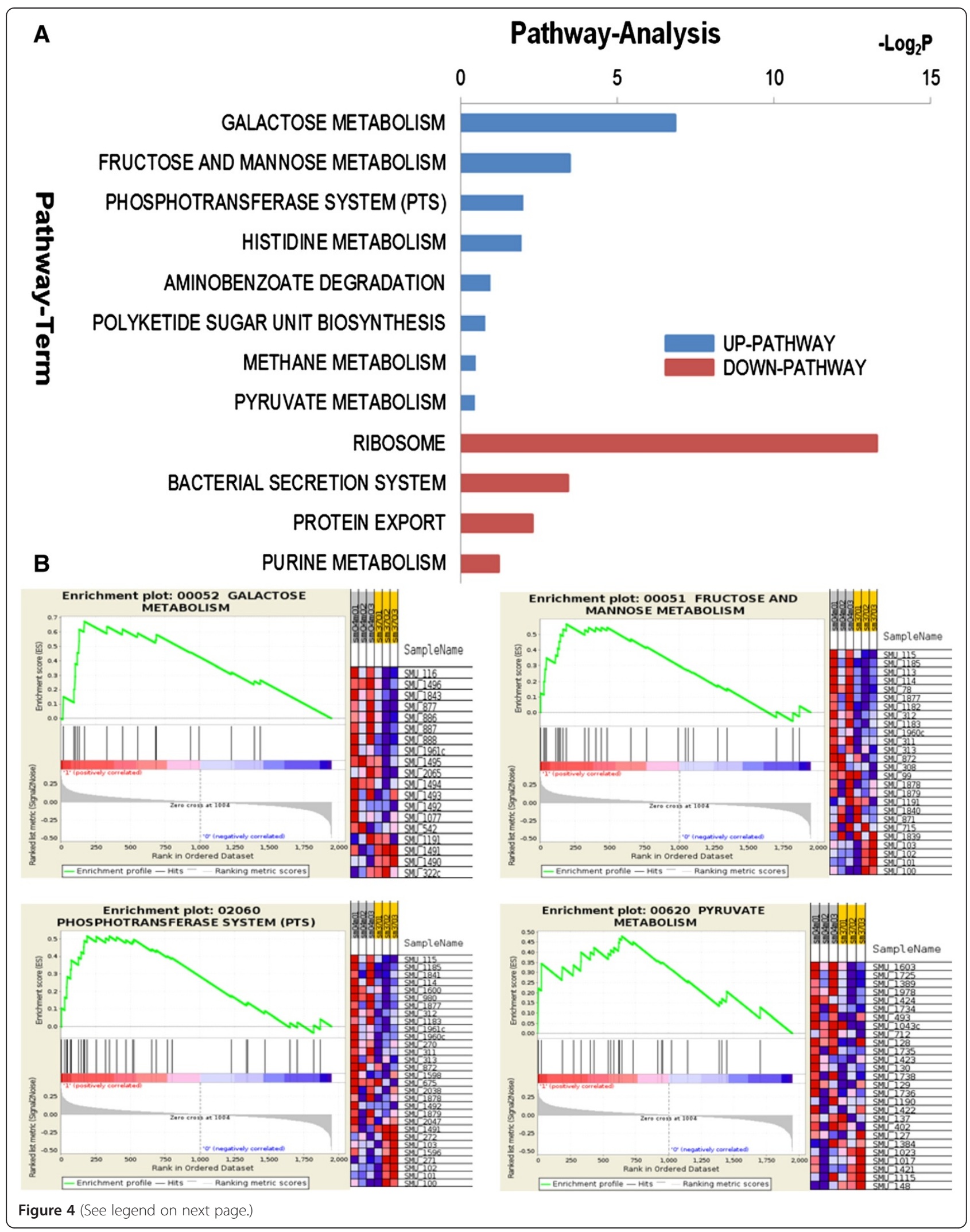


(See figure on previous page.)

Figure 4 KEGG pathway analyses for differentially expressed genes. (A) Significant up- and down-regulated pathways upon hyperosmotic challenge. $P$-value $<0.05$ and FDR $<0.25$ were used as a threshold. $\log _{2} P$ is the logarithm of $P$-value. (B) Gene set enrichment analysis (GSEA) of representative up-regulated KEGG pathways under short-term hyperosmotic stress. The four scoring plots represent galactose metabolism (upper left), fructose and mannose metabolism (upper right), phosphotransferase system (lower left) and pyruvate metabolism (lower right) with FDR of $0.010,0.054,0.110$, and 0.184 respectively. The upper left section of each plot shows the progression of the running enrichment score and the maximum peak therein. The middle left section shows the genes in the pathways as "hits" against the ranked list of genes. The bottom left section shows the histogram for the ranked list of all genes in the expression data set. The right section of each plot shows the expression intensity of genes mapped into each pathway: red (high expression value), blue (low expression value).

biofilm images were captured using a Leica TCS SP2 confocal laser scanning microscope (Leica, Germany). The confocal image stacks were analyzed by the imageprocessing software COMSTAT as described previously [29]. The three-dimensional architecture of the biofilms was visualized using AmiraTM5.0.2 (Mercury Computer Systems, Chelmsford, MS, USA).

\section{RNA isolation}

Mid-logarithmic phase cells of $S$. mutans $\left(\mathrm{OD}_{600 \mathrm{~nm}}=\right.$ $0.5)$ were incubated with $0.4 \mathrm{M}$ of $\mathrm{NaCl}$ at $37^{\circ} \mathrm{C}$ for 15 min. Cells were collected and then treated with RNAprotect reagent (Qiagen, Valencia, CA, USA) immediately. Total RNA was extracted using RNeasy Mini kits (Qiagen) as described previously [30]. Rnase-Free DNase Set (Qiagen) was used to remove genome DNA. A Nanodrop ND 1000 spectrophotometer (Thermo Fisher Scientific, Pittsburgh, PA, USA) was used to determine total RNA concentrations, and an Agilent 2100 Bioanalyser (Agilent Technologies, Santa Clara CA, USA) was used to evaluate the RNA quality (see Additional file 2 for RNA quality control). The isolated RNA was stored at $-80^{\circ} \mathrm{C}$ before use.

\section{Microarray procedures}

Streptococcus mutans UA159 (NC004350) NimbleGen Genechip $(4 * 72 \mathrm{~K})$ whole-genome array was employed for transcriptional profiling in this study. The oligoarrays included 1949 S. mutans UA159 open reading frames with twelve 24-mer probe pairs (PM/MM) per gene, and each probe was replicated 3 times. The design also included random GC and other control probes. Array images were scanned by Gene $\operatorname{Pix}^{\oplus} 4000 \mathrm{~B}$ Microarray Scanner (Axon Instruments, Union City, CA, USA). Raw data were normalized using RMA algorithm by Roche NimbleScan software version 2.6. We used the average value of each replicate probe as the signal intensity for the corresponding gene, and all the values were $\log _{2}$ transformed for further analysis. The normalized data with annotation information was processed by combining several different R/Bioconductor packages. We conducted a non-parametric statistical method contained in the RanProd package to detect the differentially expressed genes (DEG) [31]. With 100,000 permutation test, genes having a minimum 2-fold change with the false discovery rate (FDR) smaller than 0.1 were considered as DEG, indicating a significant up- or down-regulation under hyperosmotic stress. For the pathway analysis, we firstly constructed the whole $S$. mutans UA159 pathway database based on the KEGG Pathway. Then gene set enrichment analysis (GSEA) was used to determine the pathways that changed significantly in response to hyperosmotic stress [32,33].

The microarray results were further validated by quantitative RT-PCR for selected genes (see Additional file 3 for detailed primer sequences for qPCR). Quantitative RT-PCR assays were performed using a SYBR Green reverse transcription-PCR kit (TaKaRa, Dalian, China) according to the manufacturer's instructions.

\section{Statistical analysis}

We used Student's T-test to compare the non-treated control groups with treatment groups. All statistical procedures were conducted by $\mathrm{R}$ software [34]. Data were considered significantly different if the two-tailed $P$ value was $<0.05$.

\section{Microarray data accession}

All the microarray raw data have been submitted to the NCBI Gene Expression Omnibus database under the accession number GSE47170 (http://www.ncbi.nlm.nih.gov/ geo/query/acc.cgi?acc=GSE47170).

\section{Additional files}

Additional file 1: Heat map of different expressed genes of Streptococcus mutans UA159 in response to short-term hyperosmotic stress. Transcript enrichment is encoded in the heat map from low (blue) to high (red). Transcripts that show similar expression patterns are clustered together, as indicated on the top of the heat map. Gene IDs and their associated gene annotations are shown on the right of the heat map.

Additional file 2: Quality control of RNA samples by Agilent 2100 Bioanalyzer. (A) Electrophoresis files, and (B) The electropherogram of the sample well window for total RNA. The RNA Integrity Number (RIN) of all samples was $>7.0$.

Additional file 3: Oligonucleotide primers used in quantitative RT-PCR.

\section{Competing interests}

The authors declare that they have no competing interest. 


\section{Authors' contributions}

$\mathrm{CL}$ performed the majority of the experiments, analyzed the data and drafted the manuscript. YN analyzed the DNA microarray data. $K Z, C L, M L, Y L$ and RW participated in its design and coordination and helped to draft the manuscript. $Y Y$ and $X Z$ provided suggestions for the project and critically reviewed the manuscript. XX supervised the project and wrote most of the manuscript. All authors read and approved the final manuscript.

\section{Acknowledgements}

This work was supported by National Natural Science Foundation of China (grant number: 81170959), Doctoral Fund of Ministry of Education of China (grant number: 20120181120002) and National Natural Science Foundation of China (grant number: 81200782). The authors would like to thank Arne Heydorn from Section of Molecular Microbiology, the Technical University of Denmark, for proving image-processing software COMSTAT.

\section{Author details}

${ }^{1}$ State Key Laboratory of Oral Diseases, West China Hospital of Stomatology, Sichuan University, Chengdu, PR China. ${ }^{2}$ Key Lab of Bio-resources and Eco-environment of Ministry of Education, College of Life Sciences, Sichuan University, Chengdu, PR China.

Received: 16 July 2013 Accepted: 26 November 2013 Published: 1 December 2013

\section{References}

1. Lemos JA, Burne RA: A model of efficiency: stress tolerance by streptococcus mutans. Microbiology 2008, 154(Pt 11):3247-3255.

2. Lemos JA, Abranches J, Burne RA: Responses of cariogenic streptococci to environmental stresses. Current Issues Mol Biol 2005, 7(1):95-107.

3. Gao XJ, Fan Y, Kent RL Jr, Van Houte J, Margolis HC: Association of caries activity with the composition of dental plaque fluid. J Dental Res 2001, 80(9):1834-1839.

4. Margolis HC, Duckworth JH, Moreno EC: Composition of pooled resting plaque fluid from caries-free and caries-susceptible individuals. J Dental Res 1988, 67(12):1468-1475.

5. Liu YL, Nascimento M, Burne RA: Progress toward understanding the contribution of alkali generation in dental biofilms to inhibition of dental caries. Int J Oral Sci 2012, 4(3):135-140.

6. Sleator RD, Hill C: Bacterial osmoadaptation: the role of osmolytes in bacterial stress and virulence. FEMS Microbiol Rev 2002, 26(1):49-71.

7. Weber A, Jung K: Profiling early osmostress-dependent gene expression in escherichia coli using DNA microarrays. J Bacterio/ 2002, 184(19):5502-5507.

8. Epstein $\mathrm{W}$ : The roles and regulation of potassium in bacteria. Prog Nucleic Acid Re 2003, 75:293-320.

9. Ajdic D, McShan WM, McLaughlin RE, Savic G, Chang J, Carson MB Primeaux C, Tian RY, Kenton S, Jia HG, et al: Genome sequence of streptococcus mutans UA159, a cariogenic dental pathogen. P Natl Acad Sci USA 2002, 99(22):14434-14439.

10. Abranches J, Lemos JA, Burne RA: Osmotic stress responses of streptococcus mutans UA159. Fems Microbiol Lett 2006, 255(2):240-246.

11. Shemesh M, Tam A, Kott-Gutkowski M, Feldman M, Steinberg D: DNA-microarrays identification of streptococcus mutans genes associated with biofilm thickness. Bmc Microbiol 2008, 8:236

12. Shemesh M, Tam A, Aharoni R, Steinberg D: Genetic adaptation of streptococcus mutans during biofilm formation on different types of surfaces. Bmc Microbiol 2010, 10:51.

13. Ahn SJ, Wen ZT, Burne RA: Effects of oxygen on virulence traits of streptococcus mutans. J Bacterio/ 2007, 189(23):8519-8527.

14. Biswas I, Drake L, Erkina D, Biswas S: Involvement of sensor kinases in the stress tolerance response of streptococcus mutans. J Bacterio/ 2008, 190(1):68-77.

15. Klein MI, DeBaz L, Agidi S, Lee H, Xie G, Lin AH, Hamaker BR, Lemos JA, Koo $\mathrm{H}$ : Dynamics of streptococcus mutans transcriptome in response to starch and sucrose during biofilm development. Plos One 2010, 5(10):e13478.

16. Koo H, Xiao J, Klein Ml: Extracellular polysaccharides matrix-an often forgotten virulence factor in oral biofilm research. Int J Oral Sci 2009, 1(4):229-234.
17. Ahn SJ, Wen ZT, Burne RA: Multilevel control of competence development and stress tolerance in streptococcus mutans UA159. Infect Immun 2006, 74(3):1631-1642.

18. Perry JA, Jones MB, Peterson SN, Cvitkovitch DG, Levesque CM: Peptide alarmone signalling triggers an auto-active bacteriocin necessary for genetic competence. Mol MicroBiol 2009, 72(4):905-917.

19. Perry JA, Cvitkovitch DG, Levesque CM: Cell death in streptococcus mutans biofilms: a link between CSP and extracellular DNA. Fems Microbiol Lett 2009, 299(2):261-266

20. Kempf B, Bremer E: Uptake and synthesis of compatible solutes as microbial stress responses to high-osmolality environments. Arch Microbiol 1998, 170(5):319-330.

21. Matsui $R$, Cvitkovitch D: Acid tolerance mechanisms utilized by streptococcus mutans. Future MicroBiol 2010, 5(3):403-417.

22. McDougald D, Rice SA, Barraud N, Steinberg PD, Kjelleberg S: Should we stay or should we go: mechanisms and ecological consequences for biofilm dispersal. Nat Rev Microbiol 2012, 10(1):39-50.

23. $X u X$, Zhou XD, Wu CD: The Tea catechin epigallocatechin gallate suppresses cariogenic virulence factors of streptococcus mutans. Antimicrob Agents Ch 2011, 55(3):1229-1236

24. Olsen B, Murakami CJ, Kaeberlein M: YODA: software to facilitate high-throughput analysis of chronological life span, growth rate, and survival in budding yeast. BMC Bioinformatics 2010, 11:141.

25. Reuter M, Mallett A, Pearson BM, van Vliet AHM: Biofilm formation by campylobacter jejuni is increased under aerobic conditions. Appl Environ Microb 2010, 76(7):2122-2128.

26. Hasan S, Danishuddin M, Adil M, Singh K, Verma PK, Khan AU: Efficacy of E. Officinalis on the cariogenic properties of streptococcus mutans: a novel and alternative approach to suppress quorum-sensing mechanism. Plos One 2012, 7(7):e40319.

27. Xiao J, Koo H: Structural organization and dynamics of exopolysaccharide matrix and microcolonies formation by streptococcus mutans in biofilms. J Appl Microbiol 2010, 108(6):2103-2113.

28. Xiao J, Klein MI, Falsetta ML, Lu BW, Delahunty CM, Yates JR, Heydorn A, $\mathrm{Koo} \mathrm{H}$ : The exopolysaccharide matrix modulates the interaction between $3 \mathrm{D}$ architecture and virulence of a mixed-species oral biofilm. Plos Pathog 2012, 8(4):e1002623.

29. Heydorn A, Nielsen AT, Hentzer M, Sternberg C, Givskov M, Ersboll BK, Molin S: Quantification of biofilm structures by the novel computer program COMSTAT. Microbiology 2000, 146(Pt 10):2395-2407.

30. Xue $\mathrm{XL}$, Tomasch J, Sztajer H, Wagner-Dobler I: The delta subunit of RNA polymerase, RpoE, is a global modulator of streptococcus mutans environmental adaptation. J Bacteriol 2010, 192(19):5081-5092.

31. Hong FX, Breitling R, McEntee CW, Wittner BS, Nemhauser JL, Chory J: RankProd: a bioconductor package for detecting differentially expressed genes in meta-analysis. Bioinformatics 2006, 22(22):2825-2827.

32. KEGG: Kyoto Encyclopedia of Genes and Genomes. http://www.genome.jp/ kegg/.

33. Subramanian A, Kuehn H, Gould J, Tamayo P, Mesirov JP: GSEA-P: a desktop application for gene Set enrichment analysis. Bioinformatics 2007, 23(23):3251-3253.

34. The R Project for Statistical Computing. http://www.r-project.org/

\section{doi:10.1186/1471-2180-13-275}

Cite this article as: Liu et al:: Hyperosmotic response of streptococcus mutans: from microscopic physiology to transcriptomic profile. BMC Microbiology 2013 13:275 